\title{
STUDY OF PREVALENCE OF GERD IN COPD PATIENTS
}

\author{
Hina Singh ${ }^{1}$, Dhanveer Singh ${ }^{2}$, Shweta Sharma ${ }^{3}$, Anurag Tomer ${ }^{4}$
}

${ }^{1}$ Assistant Professor, Department of Medicine, LLRM Medical College, Meerut.

${ }^{2}$ Assistant Professor, Department of Medicine, SMC, Meerut.

${ }^{3}$ Assistant Professor, Department of Medicine, LLRM Medical College, Meerut.

4Junior Resident, Department of Medicine, LLRM Medical College, Meerut.

ABSTRACT
BACKGROUND
The association between gastro-oesophageal reflux symptoms and respiratory symptoms is well recognised in the setting of
asthma. It has often been suggested that patients of COPD may experience symptoms of GERD. The purpose of this study is to
calculate the prevalence of gastro-oesophageal reflux disease in COPD in Indian population.

\section{MATERIALS AND METHODS}

The study was a descriptive study and patients were selected from OPD by convenient sampling and was conducted in postgraduate Department of Medicine, LLRM Medical College; 60 cases of COPD were selected and these subjects were subjected to thorough general and systemic examination, particularly with respect to respiratory and abdominal system including upper GI endoscopy. The study was conducted over a period of 6 months. The diagnosis of COPD was made on the basis of history and PFT. Diagnosis of GERD was made on the basis of history and endoscopic findings. All subjects were also evaluated for helicobacter pylori infection by biopsy urease test.

Statistical Methods- Chi-square test was applied to see the association between COPD and GERD. P value was calculated to see the significance of association between GERD and severity of COPD, seropositivity for H. pylori and severity of COPD.

\section{RESULTS}

60 patients were enrolled $(n=60)$; out of 60,40 were male subjects $(m=40, f=20)$ and 20 were female. All subjects were subjected to PFT and FEV1 and FVC were recorded; $38.33 \%$ subjects had FEV1/FVC in range of 51\% - 60\%, 35\% subjects had FEV1/FVC in range of $41 \%-50 \%$. Out of 60 cases of COPD 38 had symptoms of GERD, on endoscopic examination 6 more cases were diagnosed as GERD, hence out of 60 cases 44 had GERD (73\%) which is a significant association ( $p$ value $<0.05 \%$ ). On assessing the corelation of GERD symptoms with lung function impairment, it was found that $47.73 \%$ cases had FEV1/FVC $<50 \%$ and these patients had daily symptoms of heart burn, regurgitation and dysphagia and on statistical analysis the association is significant. All patients were subjected to gastroscopic urease test using biopsies from antrum; out of 60, 35 cases were positive for H. pylori (58\%) and 25 were negative for H. pylori (42\%) which is significant ( $58 \%$ vs $42 \%$, p value <.05\%). On comparison of prevalence of H. pylori in patients of COPD with or without GERD, out of 44 cases of COPD with GERD 35 cases were positive for H. pylori (79\%) in comparison to 5 out of 16 cases without GERD (31.25\%) which is statistically significant (79\% vs 31.25\%, p value <.05\%). On assessing the severity of COPD in H. pylori positive and negative patients, out of 44 cases of GERD with COPD 35 were positive for H. pylori, out of which H. pylori positive status 18 (51.4\%) had FEV1/FVC $<50 \%$ and among patients without GERD out of 16 cases of $\mathrm{H}$. pylori only 5 (20\%) had FEV1/FVC $<50 \%$. This difference is statistically significant $(51.4 \%$ vs $20 \%$, p value $<.05 \%)$.

\section{CONCLUSION}

1. Prevalence of GERD is higher in COPD patients; 2. Severity of GERD increases with increase in severity of COPD; 3 . H. pylori seropositivity is associated with severity of COPD.

\section{KEYWORDS}

COPD, H. Pylori, GERD.

HOW TO CITE THIS ARTICLE: Singh H, Singh D, Sharma S, et al. Study of prevalence of GERD in COPD patients. J. Evolution Med. Dent. Sci. 2017;6(75):5397-5401, DOI: 10.14260/Jemds/2017/1170

\section{BACKGROUND}

One of the earliest studies to know the prevalence of COPD in India was carried out by Wig et al in 1964(1) in rural Delhi. The prevalence was 3.36 percent in males and 2.54 percent in females in this study. Prevalence of the above as stated by

Financial or Other, Competing Interest: None.

Submission 12-07-2017, Peer Review 06-09-2017,

Acceptance 12-09-2017, Published 18-09-2017.

Corresponding Author:

Dr. Hina Singh,

Tower B, H1/202 Classic Residency,

Rajnagar Extension, Ghaziabad-201017.

E-mail:drshwetadhanveer@gmail.com

DOI: $10.14260 /$ jemds $/ 2017 / 1170$
Vishwanathan ${ }^{2}$ was $8.1 \%$ in men and $4.6 \%$ in women. Jindal in 1993(3) reported that the prevalence was 6.2 percent in men and 3.9 percent in women in rural area and 4.2 and 1.6 percent respectively in urban area. All these studies were from north India and information from south India was scanty. Thiruvengadam et al in $1977^{(4)}$ from Madras (south India) reported the prevalence of COPD of 1.9 percent in males and 1.2 percent in females. However, Ray et al in $1995^{(5)}$ from south India found that the prevalence was 4.08 percent in males and 2.55 percent in females. Recently, the Indian Study on Epidemiology of Asthma, Respiratory Symptoms and Chronic Bronchitis in Adults (INSEARECH) involving a total of 85105 men, 84470 women from 12 urban and 11 rural sites was reported.(6) 
This study had shown that the overall prevalence of chronic bronchitis in adults $>35$ yrs. was 3.49 percent (from $1.1 \%$ in Mumbai to $10 \%$ in Thiruvananthapuram). Thus, there are wide variations in the prevalence of COPD in Indian subcontinent. Based on this study, the national burden of chronic bronchitis was estimated as 14.84 million.

\section{Pathophysiology}

Pathophysiological changes in COPD are due to the pathological changes seen in central airways, small peripheral airways, pulmonary parenchyma and pulmonary vasculature. Mucus hypersecretion is common in patients with predominant central airway involvement. Chronic obstructive pulmonary disease is characterised by an accelerated decline in FEV 171. Airflow limitation in COPD is defined as a post-bronchodilator FEV1 (forced expiratory volume in $1 \mathrm{sec}$ ) to FVC (forced vital capacity) ratio $<0.70$, usually without reversibility to bronchodilators. Bronchodilator reversibility and bronchial hyper-reactivity are variable in COPD and therefore have limited value in distinguishing COPD from bronchial asthma.(7) Overall, 23 to 42 percent of patients with COPD have responsiveness to bronchodilators and 59 percent of men and 85 percent of women with moderate COPD have airway hyperresponsiveness. The severity of airflow limitation in COPD is classified based on post-bronchodilator FEV-1 value into four groups. ${ }^{8}$

\begin{tabular}{|c|c|c|c|}
\hline $\begin{array}{c}\text { Gold } \\
\text { Stage }\end{array}$ & $\begin{array}{c}\text { COPD } \\
\text { Severity }\end{array}$ & $\begin{array}{c}\text { FEV1/FVC } \\
\text { Ratio }\end{array}$ & FEV1 Range \\
\hline 1 & Mild & $<0.70$ & $\geq 80 \%$ of normal \\
\hline 2 & Moderate & $<0.70$ & $50-79 \%$ of normal \\
\hline 3 & Severe & $<0.70$ & $30-49 \%$ of normal \\
\hline 4 & Very severe & $<0.70$ & $\begin{array}{c}<30 \% \text { of normal or }< \\
50 \% \text { of normal with } \\
\text { chronic respiratory } \\
\text { failure present }\end{array}$ \\
\hline
\end{tabular}

\section{Gastrointestinal Reflux Disease}

Gastro-oesophageal reflux disease (GERD) is defined as a condition, which develops when the reflux of stomach contents causes troublesome symptoms and/or complications. It is considered troublesome when mild symptoms occur two more days a week or moderate/severe symptoms occur one or more days a week.[9] This global definition underscores the importance of patient's symptoms in the diagnosis of GERD.

\section{Prevalence of GERD}

The Indian Society of Gastroenterology formed a task force to study the prevalence of GERD and its risk factors. The study by Bhatia et al[10] is a multi-centre prospective questionnairebased study of 3,224 urban and rural patients and reports the findings of this task force. This study reports a weekly prevalence of $7.6 \%$ in the Indian population. This journal also reports other questionnaire based cross-sectional studies by Sharma et al and Kumar et al, which also show a high prevalence of GERD (16.2\% to $18.7 \%$ ). In another study, Ramu et al evaluated the prevalence of GERD in 400 pregnant women and found that the prevalence of GERD in the first trimester was $9.5 \%$ and approximately $50 \%$ during the second and third trimester. The prevalence rate in the first trimester probably reflects the prevalence of GERD in the general population. These studies emphasise that the prevalence of GERD in India is likely to be between $8 \%$ and $19 \%$, which is comparable to GERD prevalence rates published in western countries. Very little is known about GERD in India. At this time, one thing is certain- the prevalence of GERD in India is higher than previously estimated and appears to be similar to that of the western countries. Several factors such as increasing obesity, change in diet and lifestyle, smoking, use of specific food types can affect the prevalence of GERD in this rapidly progressing society. With better understanding of the risk factors, it may be possible to target an intervention directed at the main cause of this rapid increase of GERD in India.

In western world, the prevalence of GERD in COPD ranges from $17 \%$ to $78 \%$.(11) Although, GERD is usually confined to the lower oesophagus in some individuals, it may be associated with pulmonary microaspiration of gastric contents. Possible mechanisms that may contribute to GERD in COPD originate from gastro-oesophageal dysfunction including altered pressure in the lower oesophageal sphincter (which normally protect against GERD) and changes in oesophageal motility.

Proposed respiratory contributions to the development of GERD include respiratory medications that may alter oesophageal sphincter tone and changes in respiratory mechanics with increased lung hyperinflation compromising the antireflux barrier. Although, the specific cause and effect relationship between GERD and COPD has not been fully elucidated, GERD may influence lung disease severity and has been identified as a significant predictor of acute exacerbations of COPD. Further clinical effects could include a poorer health-related quality of life and an increased cost in health care, although these factors require further clarification. There are both medical and surgical options available for the treatment of GERD in COPD and while extensive studies in this population have not been undertaken this comorbidity may be amenable to treatment.

\section{MATERIALS AND METHODS}

The study was a descriptive study and patients were selected from OPD by convenient sampling and was conducted in postgraduate Department of Medicine, LLRM Medical College. The cases were subjected to a detailed history regarding the mode of onset, presentation, duration of illness, personal antecedents including history of smoking by using preformed and pretested questionnaire. These patients were subjected to a thorough general and systemic examination as well. Chisquare test was applied to calculate the significance of association of COPD with GERD.

\section{Inclusion Criterion for COPD}

COPD patients having emphysema or chronic bronchitis were included in the study who has history of:

1. Cigarette smoking.

2. Chronic cough with sputum production for at least 3 months of the year for more than 2 consecutive years.

3. Dyspnoea.

4. Abnormal finding in PFT.

5. With FEV1/FVC as $70 \%$ of predicted.

6. < $200 \mathrm{~mL}$ or $12 \%$ improvement in FEV1/FVC after inhalation of bronchodilator. 
All patients were evaluated and severity was assessed using GOLD criterion for severity of COPD.

\section{Exclusion Criterion for COPD}

- Patient in acute exacerbation.

- Patient in congestive heart failure.

- Zollinger-Ellison syndrome.

- Alcoholic subjects (>3 drinks/day).

- Patient on theophylline or calcium channel blocker.

\section{Diagnosis of GERD}

The GERD was diagnosed on the basis of history, clinical examination and endoscopic findings.

All subjects were subjected to following investigations: Haemogram, blood sugar (fasting and post prandial), urine routine and microscopic examination, liver function test, kidney function test, pulmonary function test and upper GI endoscopy.

The diagnosis of Helicobacter pylori was made on the basis of biopsy urease test by gastroscopic urease test.

\section{Statistical Methods}

Chi-square test was applied to see the association between COPD and GERD. P value was calculated to see the significance of association between GERD and severity of COPD, H. pylori seropositivity and severity of COPD.

\section{RESULTS}

A total of 60 patients were enrolled in the study $(n=60)$ and data was collected using the pretested and preformed questionnaire and analysed by using suitable statistics.

Statistical analysis was done by using SPSS 20 trial version software. The $\mathrm{p}$ value of less than .05 is considered to be significant.

\begin{tabular}{|c|c|c|c|}
\hline Age (Years) & Male & Female & Total (\%) \\
\hline $30-40$ & 06 & 04 & 16.67 \\
\hline $40-60$ & 32 & 14 & 76.67 \\
\hline$>60$ & 02 & 02 & 6.66 \\
\hline Total & $\mathbf{4 0}$ & $\mathbf{2 0}$ & $\mathbf{1 0 0}$ \\
\hline \multicolumn{4}{|c|}{ Table 1. Age and Gender Distribution in COPD } \\
\hline
\end{tabular}

Out of which, 40 were male and 20 were female. Amongst 60 patients $16.67 \%$ belonged to age group of $30-40$ years (out of 10, 6 were males and 4 were females), $76.67 \%$ belonged to age group of 40 - 60 years (out of 46,32 were males and 14 were females), $6.66 \%$ of patients were aged > 60 years (out of 4,2 were males and 2 were females).

\begin{tabular}{|c|c|c|}
\hline FEV1/FVC & No. of Subjects & Percentage \\
\hline$<40$ & 6 & 10 \\
\hline $41-50$ & 21 & 35 \\
\hline $51-60$ & 23 & 38.33 \\
\hline $61-69$ & 10 & 16.67 \\
\hline Total & $\mathbf{6 0}$ & $\mathbf{1 0 0}$ \\
\hline \multicolumn{2}{|c|}{ Table 2. Degree of FEV1/FVC in COPD Patients } \\
\hline
\end{tabular}

All subjects were subjected to PFT and FEV1 and FVC were calculated, $38.33 \%$ subjects had FEV1/FVC in range of $51-60 \%, 35 \%$ subjects had FEV1/FVC in range of $41-50 \%$,
$10 \%$ had FEV1/FVC $<40 \%, 16.67 \%$ had FEV1/FVC in range of $61-69 \%$.

\begin{tabular}{|c|c|c|c|c|}
\hline \multirow{2}{*}{ Gender } & \multicolumn{2}{|c|}{ Having GERD } & \multicolumn{2}{c|}{ Not Having GERD } \\
\cline { 2 - 5 } & NO. & $\%$ & NO. & $\%$ \\
\hline Male & 30 & 75.00 & 10 & 25.1 \\
\hline Female & 08 & 40.00 & 12 & 60.0 \\
\hline \multicolumn{3}{|c|}{ Table 3. Distribution of GERD in COPD Patients } \\
according to Symptoms (Heartburn \\
Regurgitation Dysphagia)
\end{tabular}

\begin{tabular}{|c|c|c|}
\hline Gender & Having GERD & Not Having GERD \\
\hline Male & 25.3 & 14.7 \\
\hline Female & 12.7 & 7.33 \\
\hline \multicolumn{2}{|c|}{ On Applying Chi-Square Test Contingency } \\
Table Result are as Follows \\
\hline
\end{tabular}

Out of 60 cases of COPD 38 had symptoms of GERD, out of which 30 were male and 08 patients were female indicating a male preponderance of GERD among smokers. On applying ]$^{2}=7.03$ and $\mathrm{df}=1, \mathrm{p}$ value is 0.008 which is highly significant.

\begin{tabular}{|c|c|c|c|c|}
\hline \multirow{2}{*}{ Sex } & \multicolumn{2}{|c|}{ Having GERD } & Not Having GERD \\
\cline { 2 - 5 } & No. & $\%$ & No. & $\%$ \\
\hline Male & 33 & 75 & 6 & 37.5 \\
\hline Female & 11 & 25 & 10 & 62.5 \\
\hline Total & $\mathbf{4 4}$ & $\mathbf{1 0 0}$ & $\mathbf{1 6}$ & $\mathbf{1 0 0}$ \\
\hline \multicolumn{4}{|c|}{ Table 4. Percentage of GERD } \\
(After Endoscopy) in COPD Patients \\
\hline
\end{tabular}

\begin{tabular}{|c|c|c|}
\hline Sex & Having GERD & Not Having GERD \\
\hline Male & 28.6 & 10.4 \\
\hline Female & 15.4 & 5.60 \\
\hline \multicolumn{2}{|c|}{ On Applying Chi-Square Test Contingency Table } \\
Result are as Follows \\
\hline
\end{tabular}

Table 4 shows that when 22 patients of COPD without GERD were subjected to endoscopy, 6 more cases of GERD were discovered raising the total to 44 cases of GERD out of 60 subjects of COPD making a significant association ( $\mathrm{p}$ value $<.05$ ). On applying ? $^{2}=7.25$ and $\mathrm{df}=1, \mathrm{p}$ value is 0.007 which is highly significant.

\begin{tabular}{|c|c|c|c|}
\hline \multirow{2}{*}{$\begin{array}{c}\text { Stage of } \\
\text { COPD }\end{array}$} & \multicolumn{2}{|c|}{ No. of Patients } & \multirow{2}{*}{$\begin{array}{c}\text { Symptoms of GERD } \\
\text { (Heartburn and } \\
\text { Regurgitation) }\end{array}$} \\
\hline & No. & $\%$ & \\
\hline 0 & 6 & 13.64 & Once a week (Heartburn) \\
\hline 1 & 7 & 15.90 & $\begin{array}{c}\text { Twice a week (Heartburn/ } \\
\text { Regurgitation) }\end{array}$ \\
\hline 2 & 17 & 38.64 & Daily Symptoms \\
\hline 3 & 14 & 31.82 & $\begin{array}{l}\text { Daily Symptoms with } \\
\text { Dysphagia }\end{array}$ \\
\hline
\end{tabular}

Table 5 shows the co-relation of severity of GERD in patients of COPD.

Out of 44 patients of GERD, 38.64\% patients had daily symptoms of heartburn/regurgitation and about $31.82 \%$ patients had daily symptoms along with dysphagia. 


\begin{tabular}{|c|c|c|c|c|}
\hline \multirow{2}{*}{ GERD } & No. of & \multicolumn{3}{|c|}{ FEV1/FVC } \\
\cline { 3 - 5 } & Patients & $\mathbf{7 1 - 7 9 \%}$ & $\mathbf{5 1 - 7 0 \%}$ & $\mathbf{3 0 - 5 0 \%}$ \\
\hline Once a week & 6 & 4 & 1 & 1 \\
\hline Twice a week & 7 & 4 & 1 & 2 \\
\hline Daily & 17 & 1 & 6 & 10 \\
\hline $\begin{array}{c}\text { Daily with } \\
\text { Dysphagia }\end{array}$ & 14 & 0 & 6 & 8 \\
\hline Total & $\mathbf{4 4}$ & $\mathbf{9 ( 2 0 . 4 5 )}$ & $\mathbf{1 4}(31.82)$ & $\mathbf{2 1}(\mathbf{4 7 . 7 3 )}$ \\
\hline \multicolumn{5}{|c|}{ Table 6. Co-relation of GERD } \\
with Lung Function Impairment in COPD \\
\hline
\end{tabular}

\begin{tabular}{|c|c|c|c|c|}
\hline \multirow{2}{*}{ GERD } & \multirow{2}{*}{$\begin{array}{c}\text { No. of } \\
\text { Patients }\end{array}$} & \multicolumn{3}{|c|}{ FEV1/FVC } \\
\hline & & $71-79 \%$ & $51-70 \%$ & $30-50 \%$ \\
\hline Once a week & 6 & 1.25 & 1.91 & 2.86 \\
\hline Twice a week & 7 & 1.43 & 2.23 & 3.34 \\
\hline Daily & 17 & 3.48 & 5.41 & 8.11 \\
\hline $\begin{array}{l}\text { Daily with } \\
\text { Dysphagia }\end{array}$ & 14 & 2.86 & 4.45 & 6.68 \\
\hline \multicolumn{5}{|c|}{$\begin{array}{c}\text { On applying Chi-Square Test Contingency } \\
\text { Table Result are as Follows }\end{array}$} \\
\hline
\end{tabular}

Table 6 shows the co-relation of GERD symptoms with lung function impairment. It was found that $47.73 \%$ cases had FEV1/FVC $<50 \%$ and these patients had daily symptoms of heartburn, regurgitation and dysphagia and the association is significant ( $\mathrm{p}$ value $<.05$ ). On applying $\mathbf{0}^{2}=19.7$ and $\mathrm{df}=9$, $\mathrm{p}$ value is .020 which is significant.

\begin{tabular}{|c|c|c|}
\hline \multirow{2}{*}{ No. of Patients with COPD } & \multicolumn{2}{|c|}{ Helicobacter Pylori } \\
\cline { 2 - 3 } & Positive & Negative \\
\hline 60 & 35 & 25 \\
\hline Table 7. Prevalence of H. pylori in COPD Patients \\
\hline
\end{tabular}

All patients were subjected to gastroscopic urease test using biopsies from antrum, Table 7 shows that out of 60,35 cases were positive for $\mathrm{H}$. pylori (58\%) and 25 were negative for $\mathrm{H}$. pylori (42\%) which is a significant association.

\begin{tabular}{|c|c|c|c|c|}
\hline \multirow{2}{*}{} & \multicolumn{3}{|c|}{ COPD with GERD } & \multicolumn{2}{c|}{ COPD without GERD } \\
\cline { 2 - 5 } & No. & $\mathbf{\%}$ & No. & \% \\
\hline H. pylori Positive & 35 & 79.54 & 5 & 31.25 \\
\hline H. pylori Negative & 09 & 20.46 & 11 & 68.75 \\
\hline Total & $\mathbf{4 4}$ & $\mathbf{1 0 0}$ & $\mathbf{1 6}$ & $\mathbf{1 0 0}$ \\
\hline Table 8. Comparison of Prevalence of \\
H. pylori in Patients of COPD with or without GERD \\
\hline
\end{tabular}

Table 8 shows that out of 44 cases of COPD with GERD, 35 cases were positive for $\mathrm{H}$. pylori $(79 \%)$ in comparison to 5 out of 16 cases without GERD (31.25\%) which is statistically significant ( $79 \%$ vs. $31.25 \%$, P value <.05\%). On applying $?^{2}$ $=12.3$ and $\mathrm{df}=1, \mathrm{p}$ value is 0.000 which is highly significant.

\begin{tabular}{|c|c|c|c|}
\hline \multirow{2}{*}{$\begin{array}{c}\text { H. pylori } \\
\text { Positive Patients }\end{array}$} & \multicolumn{3}{|c|}{ FEV1/FVC } \\
\cline { 2 - 4 } & $71-79 \%$ & $51-70 \%$ & $30-50 \%$ \\
\hline 35 & $5(14.28)$ & $12(34.28)$ & $18(51.42)$ \\
\hline \multirow{3}{*}{$\begin{array}{c}\text { H. pylori Negative } \\
\text { Patients }\end{array}$} & $71-79 \%$ & $51-70 \%$ & $30-50 \%$ \\
\hline 25 & $11(44)$ & $9(36)$ & $5(20)$ \\
\hline \multicolumn{2}{|c|}{$\begin{array}{r}\text { Table 9. Severity of COPD in H. pylori } \\
\text { Positive and Negative Patient }\end{array}$} \\
\hline
\end{tabular}

\begin{tabular}{|c|c|c|c|}
\hline \multirow{2}{*}{ H. pylori Positive Patients } & \multicolumn{3}{|c|}{ FEV1/FVC } \\
\hline & $71-79 \%$ & $51-70 \%$ & $30-50 \%$ \\
\hline 35 & 9.94 & 13 & 21.7 \\
\hline \multirow{2}{*}{ H. pylori Negative Patients } & \multicolumn{3}{|c|}{ FEV1/FVC } \\
\hline & $71-79 \%$ & $51-70 \%$ & $30-50 \%$ \\
\hline 25 & 6.06 & 7.95 & 13.3 \\
\hline \multicolumn{4}{|c|}{$\begin{array}{c}\text { On applying Chi-Square Test Contingency } \\
\text { Table Result are as Follows }\end{array}$} \\
\hline
\end{tabular}

On assessing the severity of COPD in H. pylori positive and negative patients (Table 10), out of 44 cases of GERD with COPD 35 were positive for $\mathrm{H}$. pylori, out of which $\mathrm{H}$. pylori positive status 18 (51.4\%) had FEV1/FVC < 50\% and among patients without GERD, out of 16 cases of $\mathrm{H}$. pylori only $5(20 \%)$ had FEV $1 /$ FVC $<50 \%$. This difference is statistically significant $(51.4 \%$ vs $20 \%$, p value $<.05 \%)$. On applying ? $^{2}=15.3$ and $\mathrm{df}=3$, p value is .002 , which is highly significant.

\section{DISCUSSION}

The aim of the study was to calculate the prevalence of GERD in patients of COPD and to assess the severity of GERD with COPD, study also determined the prevalence of $\mathrm{H}$. pylori in patients of COPD with GERD.

60 patients of COPD were included in the study and were subjected to history, clinical examination and investigational workup. The majority belonged to 40 - 60 years' age group, out of 60 subjects 40 were male and 20 were female. PFT was done in all subjects and forced expiratory volume in 1 sec. and forced vital capacity was measured and FEV1/FVC was calculated. Max. patients (38.33\%) had FEV1/FVC in the range of $51-60 \%$.

Followed by $35 \%$ patients who had FEV1/FVC in the range of $41-50 \%$.

Out of 60 subjects of COPD 38 had symptoms of GERD, out of which 30 were male and 08 were female indicating a male preponderance of GERD among smokers, when 22 patients of COPD without GERD were subjected to endoscopy 6 more cases of GERD were discovered raising the total to 44 cases of GERD out of 60 cases of COPD making a significant association ( $\mathrm{p}$ value $<.05$ ).

On assessing the severity of GERD symptoms in patients of COPD, it was found that patients of stage 2 and 3 COPD (acc. to GOLD criterion) had almost daily symptoms, about $38 \%$ had symptoms of heartburn and regurgitation and $32 \%$ had dysphagia.

On assessing the severity of GERD symptoms in patients of lung function impairment in patients of COPD, it was found that $47.33 \%$ patients had FEV1/FVC $<50 \%$ and $31.82 \%$ cases had FEV1/FVC > 50\%.

All patients were subjected to gastroscopic urease test using biopsies from antrum and out of 60,35 cases were positive for $\mathrm{H}$. pylori (58\%) and 25 were negative for $\mathrm{H}$. pylori (42\%) which is significant ( $58 \%$ vs $42 \%$ ).

On assessing the severity of COPD in H. pylori positive and negative patients (Table 10), out of 44 cases of GERD with COPD 35 were positive for $\mathrm{H}$. pylori, out of which $\mathrm{H}$. pylori positive status $18(51.4 \%)$ had FEV1/FVC $<50 \%$ and among patients without GERD, out of 16 cases of $\mathrm{H}$. pylori only $5(20 \%)$ had FEV1/FVC $<50 \%$. This difference is statistically significant $(51.4 \%$ vs $20 \%$, p value $<.05 \%)$. 


\section{CONCLUSION}

We finally conclude that-

1. Prevalence of GERD is higher in patients of COPD.

2. Severity of GERD increases with increase in severity of COPD.

3. Prevalence of $\mathrm{H}$. pylori is high in COPD.

4. H. pylori seropositivity is associated with severity of COPD.

\section{REFERENCES}

[1] Wig KL, Guleria JS, Bhasin RC, et al. Certain clinical and epidemiological patterns of chronic obstructive lung disease as seen in Northern India. Indian J Chest Dis 1964;6:183-94.

[2] Viswanathan R. Epidemiology of chronic bronchitis: morbidity survey in Patna urban area. Indian J Med Res 1966;54(1):105-11.

[3] Jindal SK. A field study on follow up at 10 years of prevalence of chronic obstructive pulmonary disease \& peak expiratory flow rate. Indian J Med Res 1993;98:20-6.

[4] Thiruvengadam KV, Raghava TP, Bhardwaj KV. Survey of prevalence of chronic bronchitis in Madras city. In: Viswanathan R, Jaggi OP. (eds). Advances in chronic obstructive lung disease. Delhi: Asthma and Bronchitis Foundation of India; 1977:59-6.
[5] Ray D, Abel R, Selvaraj KG. A 5-yr prospective epidemiological study of chronic obstructive pulmonary disease in rural South India. Indian J Med Res 1995;101:238-44.

[6] Jindal SK, Aggarwal AN, Gupta D, et al. Indian study on epidemiology of asthma, respiratory symptoms and chronic bronchitis in adults (INSEARCH). Int J Tuberc Lung Dis 2012;16(9):1270-7.

[7] Han MK, Wise R, Mumford J, et al. NETT Research Group. Prevalence and clinical correlates of bronchoreversibility in severe emphysema. Eur Respir J 2010;35(5):1048-56.

[8] Global Initiative for Chronic Obstructive Lung Disease. Global strategy for the diagnosis, management and prevention of Chronic Obstructive Pulmonary Disease (Revised 2011). GOLD_Report_2011_Feb21_pdf, accessed on September 16, 2012.

[9] Chang CS, Poon SK, Lien HC, et al. The incidence of reflux esophagitis among the Chinese. Am J Gastroenterol 1997;92(4):668-71.

[10] Shah SS, Bhatia SJ, Mistry FP. Epidemiology of dyspepsia in the general population in Mumbai. Indian J Gastroenterol 2001;20(3):103-6.

[11] Casanova C, Baudet JS, del Valle Velasco M, et al. Increased gastro-oesophageal reflux disease in patients with severe COPD. Eur Respir J 2004;23(6):841-5. 